\title{
O regime jurídico do tombamento e a proteção do patrimônio cultural
}

\author{
El regimén jurídico del tombamento y la protección del patrimonio \\ cultural
}

\section{The legal regime of tombamento and the protection of cultural heritage}

\author{
Renato Ramalho \\ Fábio Brito Ferreiraii
}

Palavras chave:

Patrimônio cultural

Intervenção do Estado na

Propriedade

Tombamento

\section{Resumo:}

Foi somente a partir do século $X X$ que, na maior parte do mundo, se desenvolveu efetivamente o processo de proteção aos valores culturais da humanidade. No âmbito internacional, foram firmados diversos tratados e convenções reconhecendo a importância do patrimônio cultural, e impondo aos Estados a responsabilidade de defendê-los. No Brasil, a Constituição de 1988 foi um marco para a promoção da cultura de nosso povo, determinando que o Poder Público nacional deve utilizar de instrumentos administrativos para sua proteção. Dentre eles, destaca-se o instituto do tombamento, espécie de intervenção na propriedade, pelo Estado, que impõe certas obrigações ao proprietário, sem retirar-lhe o domínio sobre o bem. Tal instituto vem sendo cada vez mais utilizado em nosso país, eis que se mostra como um eficiente mecanismo para a preservação de bens (principalmente imóveis) que carregam importante valor cultural. Assim, o presente trabalho trata do regime jurídico do tombamento, destacando suas características e efeitos. 


\section{Resumen:}

En la mayor parte del mundo, solamente en siglo $X X$ que se ha desarrollado efectivamente el proceso de protección de los valores culturales de la humanidad. Internacionalmente, fueron firmados diversos tratados y convenciones reconociendo la importancia del patrimonio cultural, imponiendo la responsabilidad de los Estados para su defensa. En Brasil, la Constitución de 1988 fue un hito para la promoción de la cultura de nuestro pueblo, determinando que el Poder Publico nacional debe utilizar herramientas administrativas para su protección. Entre ellos, si destaca el procedimiento del tombamento, que es un tipo de intervención en la propiedad por el Estado, que impone ciertas obligaciones para con el propietario sin remover su propiedad sobre el bien. Dicho procedimiento está siendo utilizado cada vez más en nuestro país, dado que si muestra como un eficiente mecanismo para la preservación de bienes (principalmente propiedades inmobiliarias) que poseen importante valor cultural. Así, el presente artículo trata del régimen legal del tombamento, destacando sus características y efectos.

\section{Palabras clave:}

Patrimonio cultural

Intervención Estatal en la Propriedad

Tombamento

\section{Keywords:}

Cultural Heritage

State intervention in the property

\section{Tombamento}

\section{Abstract:}

It was not until the twentieth century that, in most of the world, the process of protection to the cultural values of humanity was effectively developed. Internationally, several Treaties and Conventions were signed recognizing the importance of cultural heritage, and imposing on States the responsibility to defend them. In Brazil, the 1988 Constitution was a milestone for the promotion of culture of our people, determining that the National Government must use administrative tools for its protection. Among them, there is the tombamento institute, a kind of intervention on the property, by the State, which imposes certain obligations to the owner without removing his dominion over the good. This institute has been increasingly used in our country, since its shown as an efficient mechanism for the preservation of assets (mainly immovable ones) that carry important cultural value. Thus, the present work deals with the legal regime of tombamento, highlighting their characteristics and effects. 


\section{0 regime jurídico do tombamento e a proteção do patrimônio cultural}

\section{Notas introdutórias: Valores culturais na ótica internacional e nacional}

Atualmente, existem diversos institutos previstos pela legislação brasileira que possuem estrita relação com a proteção de valores culturais de nosso povo. Dentre eles, destaca-se o tombamento, cujo regime jurídico será analisado no presente trabalho. Entretanto, a defesa de valores ligados à história e à identidade de uma comunidade é decorrente de um longo e inacabado processo histórico.

Segundo Reale (2002, p. 244), "a cultura não é senão a concretização ou atualização da liberdade, do poder que o homem tem de reagir aos estímulos naturais de maneira diversa do que ocorre com os outros animais". É possível complementar as palavras de Reale com o pensamento de Recasens Siches (1975, p. 103), para quem é por meio da cultura que ocorre a efetivação de valores até então tidos como ideais; esses valores, contudo, não são constantes. Assim, todo bem cultural tem um significado circunstancial, ou seja, adveio de uma situação histórica para atender as necessidades humanas daquele determinado momento.

A comunidade internacional, nos dias atuais, mobiliza-se a fim de garantir que o patrimônio cultural seja considerado como um direito pertencente a toda a humanidade.

Nesse sentido, o contexto onde se insere a garantia pelo Estado de valores vinculados à cultura é traçado, principalmente, em virtude do fenôme- no de internacionalização dos direitos humanos, desenvolvido a partir de meados do século XX (PIOVESAN, 2004, p. 131), e que não deixou de fora as questões culturais.

Os direitos culturais são aqueles relacionados à participação do indivíduo na vida cultural de determinada comunidade, bem como à manutenção do patrimônio histórico e natural, que concretizam a identidade e memória de determinado povo (RAMOS, 2005, p. 92).

Em âmbito internacional, após a Segunda Guerra Mundial, diversos foram os instrumentos internacionais destinado à proteção do patrimônio histórico e cultural da humanidade. Já na Carta das Nações Unidas de 1945, houve a previsão de que a ONU buscaria favorecer a "cooperação internacional, de caráter cultural' "iii. Nesse mesmo ano, foi criada a Organização das Nações Unidas para a Educação, a Ciência e a Cultura - UNESCO, o mais importante ator internacional de proteção à cultura desde então.

Borges $^{i v}$ destaca que, com o Pacto Internacional de Direitos Econômicos, Sociais e Culturais, houve o reconhecimento internacional de que cada indivíduo tem o direito de participar da vida cultural. O Pacto, inclusive, prevê a obrigação do Estado de instituir políticas para a conservação, desenvolvimento e difusão da cultura (artigo 15)v.

Em 1972, foi adotada, no âmbito da ONU, a Convenção para a Proteção do Patrimônio Mundial, Cultural e Naturalvi, que representa um grande avanço para o reconhecimento de obrigações internas e internacionais para a proteção de questões de relevância cultural. A Convenção trouxe a definição de patrimônio cultural da seguinte forma: 
I. DEFINIÇÃO DE PATRIMÔNIO CULTURAL E NATURAL

ARTIGO 1

Para os fins da presente Convenção, são considerados "patrimônio cultural":

- os monumentos: obras arquitetônicas, esculturas ou pinturas monumentais, objetos ou estruturas arqueológicas, inscrições, grutas e conjuntos de valor universal excepcional do ponto de vista da história, da arte ou da ciência,

- os conjuntos: grupos de construções isoladas ou reunidas, que, por sua arquitetura, unidade ou integração à paisagem, têm valor universal excepcional do ponto de vista da história, da arte ou da ciência,

- os sítios: obras do homem ou obras conjugadas do homem e da natureza, bem como áreas, que incluem os sítios arqueológicos, de valor universal excepcional do ponto de vista histórico, estético, etnológico ou antropológico.

A Convenção de 1972 ainda criou o Comitê do Patrimônio Mundial, responsável pela elaboração e divulgação da "Lista de Patrimônio Mundial"vii , que são bens de ordem cultural ou natural considerados de valor universal excepcional (artigo 11). Desde então, vários foram os mecanismos constituídos no âmbito das Nações Unidas destinadas à proteção da propriedade cultural da sociedade humana.

Nas palavras de Silva (2010, p. 92), "a inscrição na Lista do Patrimônio Mundial tem o condão jurídico de tornar o bem integrante do patrimônio cultural e natural da humanidade que passa a receber uma proteção nacional e internacional".

Além do Sistema Global, os sistemas regionais de proteção aos direitos humanos também têm assumido um relevante papel na proteção da cultura dos povos. Exemplo disso ocorre no continente americano, por meio da Organização dos Estados Americanos, que instituiu o Sistema Interamericano de Direitos Humanos, defendendo, com base na Convenção Interamericana de Direitos Humanos viii, e em outros instrumentos interamericanos, a cultura como um valor inerente a qualquer comunidade, e cuja proteção é de responsabilidade dos Estados.

No Brasil, o reconhecimento de que a promoção da cultura é um dever do Estado é um fenômeno recente em nossa história. Até 1808, por exemplo, quando o Brasil ainda era uma colônia portuguesa, era vedada qualquer produção ou edição de livros por brasileiros. A história só poderia ser contada por estrangeiros, o que demonstra a maneira limitativa com que a monarquia portuguesa conduzia a vida cultural brasileira.

Com efeito, em nosso país, a proteção de bens de interesse cultural foi desenvolvida, principalmente, com o declínio dos governos militares. No ano de 1985 , foi criado um Ministério da Culturaix, órgão específico com a competência de estabelecer políticas sobre patrimônio histórico, arqueológico, artístico e cultural, entre outros assuntos referentes ao meio cultural.

Contudo, foi com a Constituição de 1988 que se desencadearam expressivos avanços no que concerne à promoção dos valores sociais, históricos e ambientais em nosso país (BENJAMIN, 2007). A Carta Magna de 1988 atribuiu ao patrimônio cultural um privilegiado status jurídico, destacando que sua proteção é dever do Estado.

Nesse sentido, o art. 215, caput, da Constituição Federal dispõe que o "Estado garantirá a todos o pleno exer- 
cício dos direitos culturais e acesso às fontes da cultura nacional, e apoiará e incentivará a valorização e a difusão das manifestações culturais".

Nossa Carta Política ainda reconhece o direito à cultura daquelas comunidades que participaram do processo histórico de formação de nosso povo. Segundo o art. $215, \S 1^{\circ}$, "o Estado protegerá as manifestações das culturas populares, indígenas e afro-brasileiras, e das de outros grupos participantes do processo civilizatório nacional". No $\S 2^{\circ}$ do mesmo artigo, atribui à lei ordinária a competência de regulamentar a fixação de datas simbólicas para os diferentes segmentos étnicos brasileiros.

Ressalte-se ainda que a Emenda Constitucional $n^{\circ} 48$ de 2005 acrescentou o $\S 3^{\circ}$ do artigo 215 , estabelecendo o Plano Nacional de Cultura, com cinco objetivos principais: a) defesa e valorização do patrimônio cultural brasileiro (inciso I); b) produção, promoção e difusão de bens culturais (inciso II); c) formação de pessoal qualificado para a gestão da cultura em suas múltiplas dimensões (inciso III); d) democratização do acesso aos bens de cultura (inciso IV), e; e) valorização da diversidade étnica e regional (inciso $\mathrm{V}$ ).

$\mathrm{O}$ art. 216 da nossa Lei Maior, por sua vez, é de fundamental importância para se compreender o conceito constitucional de patrimônio cultural:

Art. 216. Constituem patrimônio cultural brasileiro os bens de natureza material e imaterial, tomados individualmente ou em conjunto, portadores de referência à identidade, à ação, à memória dos diferentes grupos formadores da sociedade brasileira, nos quais se incluem:

I - as formas de expressão;

II - os modos de criar, fazer e viver;
III - as criações científicas, artísticas e tecnológicas;

IV - as obras, objetos, documentos, edificações e demais espaços destinados às manifestações artístico-culturais;

$\mathrm{V}$ - os conjuntos urbanos e sítios de valor histórico, paisagístico, artístico, arqueológico, paleontológico, ecológico e científico.

Adiante-se que, para os fins do presente trabalho, é possível destacar, através da leitura do dispositivo supra, os principais bens sobre os quais recai o tombamento (como veremos a seguir), a saber, "as obras, objetos documentos edificações e demais espaços destinados às manifestações artístico-culturais" (inciso IV), bem como "os conjuntos urbanos e sítios de valor histórico, paisagístico, artístico, arqueológico, paleontológico, ecológico e científico" (inciso V).

Portanto, é possível notar, nas palavras de Carvalho Filho (2012, p. 794), "o intuito de dar cada vez mais realce aos valores culturais"; seja em âmbito internacional ou interno. Não há mais, em nossa sociedade, qualquer espaço para pensamentos contrários à responsabilidade estatal no que concerne à defesa do patrimônio cultural. Nesse contexto é que se insere o instituto do tombamento, um dos principais instrumentos para a proteção da cultura nacional.

\section{Conceito}

O termo tombamento é de origem portuguesa, significando o registro do patrimônio de alguém em livros específicos num órgão de Estado que cumpre tal função.

No Brasil, o tombamento trata-se de uma forma restritiva de intervenção na propriedade através da qual o Estado bus- 
ca preservar o patrimônio cultural nacional (Idem, p. 792).

Moreira Neto (1989, p. 318) explica, precisamente, que o tombamento trata-se de

intervenção ordinatória e concreta do Estado na propriedade privada, limitativa de exercício de direitos de utilização e disposição, gratuita, permanente e indelegável, destinada à preservação, sob regime especial, dos bens de valor cultural, histórico, arqueológico, artístico, turístico ou paisagístico.

Com efeito, o objetivo do Poder Público, ao intervir na propriedade de particulares, por meio do tombamento, é a preservação da memória nacional, a qual Carvalho Filho (Op cit, p. 793) conceitua como o "aspecto histórico de um país, como por todos reconhecido, que faz parte da própria cultura do povo e representa fonte sociológica de identificação dos vários fenômenos sociais, políticos e econômicos" existentes na atualidade.

Através do tombamento, o Estado sobreleva o interesse público sobre o privado, a fim de preservar bens que agregam à nossa comunidade valores de caráter histórico, paisagístico, artísti$\mathrm{co}$, arqueológico, paleontológico, ecológico e científico.

Inúmeros são os bens tombados na atualidade, em nosso país. Os mais comuns deles tratam-se de imóveis que representam a arquitetura de séculos passados. É possível, inclusive, o tombamento de bairros que detêm importante valor histórico-cultural. Podemos citar, por exemplo, o Centro Histórico das cidades de Salvador (Bahia), de Olinda (Pernambuco) e de Ouro Preto (Minas Gerais) ${ }^{\mathrm{x}}$.

\section{Características}

A Constituição Federal de 1988 impõe ao Poder Público ${ }^{x i}$ a responsabilidade de garantir a todos o exercício dos direitos culturais e a proteção do patrimônio cultural. Essa atribuição é praticada mediante determinados mecanismos administrativos previstos na própria Carta Política.

Nesse sentido, o art. $216, \S 1^{\circ}$, da $\mathrm{CF}$, dispõe que o Estado, em colaboração com a comunidade, "promoverá e protegerá o patrimônio cultural brasileiro, por meio de inventários, registros, vigilância, tombamento e desapropriação, e de outras formas de acautelamento e preservação".

Por outro lado, o $\S 2^{\circ}$ do mencionado dispositivo prevê que "cabem à administração pública, na forma da lei, a gestão da documentação governamental e as providências para franquear sua consulta a quantos dela necessitem".

Dessa forma, é possível perceber que o tombamento é apenas um dos instrumentos de proteção do patrimônio público. Segundo o texto constitucional, ele deve ser regulamentado, assim como os demais mecanismos, mediante lei ordinária.

A lei infraconstitucional regulamentadora do tombamento é o Decreto- Lei ${ }^{\circ}$ 25 de 30 de novembro de 1937, que, em que pese algumas desatualizações, rege as normas gerais para o instituto ora analisado, classificando os documentos de registro em: Livro do Tombo Arqueológico, Etnográfico e Paisagístico; Livro do Tombo Histórico; Livro do Tombo das Belas-Artes, e; Livro do Tombo das Artes Aplicadas.

Não bastasse sua expressa previsão no art. $216, \S 1^{\circ}$, da CF, o tombamento ainda encontra seu fundamento constitucional no princípio da função so- 
cial da propriedade (arts. $5^{\circ}, \mathrm{XXXIII,} \mathrm{e}$ 170, III, da CF). E não poderia ser diferente: se o tombamento é uma das formas de intervenção do Estado na propriedade, é porque se configura como um mecanismo constitucional para adequar o interesse privado à propriedade ao interesse público à cultura.

Quando se trata de intervenção estatal na propriedade, as peculiares que distinguem um instituto de outro estão ligadas, normalmente, a delimitação de seus objetos. No caso do tombamento, uma característica marcante é que ele incide sobre bens móveis e imóveis, conforme disposto no art. $1^{\circ}$ do Decreto-Lei $n^{\circ}$ 25/1937. Entretanto, é preciso ressaltar que esse instituto apenas recai sobre bens com relevância para o patrimônio cultural brasileiro; meros vínculos particulares e individuais com um bem não têm o condão de provocar seu tombamento.

Para alguns autores, o patrimônio cultural estaria inserido no contexto do direito ambiental; assim, bens dotados de valor cultural poderiam ser considerados como integrantes do meio ambiente cultural (COELHO ; FERREIRA, 2011, p. 68). Entretanto, é preciso ter cautela ao se formular essa conclusão. Várias vezes, o tombamento tem sido utilizado para fins exclusivos de proteção ambiental à flora e a fauna. Ocorre que, conforme ensina Meirelles (1998, p. 467), tal aplicação é considerada errônea, eis que o tombamento não pode servir de sucedâneo dos instrumentos ambientais próprios de proteção à natureza previstos em nossa legislação, tal como as unidades de conservação.

O tombamento deve ser precedido de procedimento administrativo, que deve respeitar o devido processo legal e a ampla defesa e o contraditório (art. $5^{\circ}$, LIV e LV, da Constituição Federal), conforme a sistemática prevista no item 5 do presente trabalho.
Ressalte-se que, segundo entendimento do Superior Tribunal de Justiça STJ, a responsabilidade do Estado para a proteção do patrimônio cultural é plena e abrangente, de modo que "em situação de emergência, mesmo sem comunicação do proprietário, tem a obrigação de providenciar o imediato início dos trabalhos necessários para a conservação do bem tombado".

Os arts. 19 e 20 do Decreto- Lei $n^{\circ}$ 25/37 atribuem à competência da fiscalização sobre os bens tombados ao Serviço do Patrimônio Histórico e Artístico Nacional, que posteriormente, com a edição do Decreto n. 66.967 de 27 de julho de 1970, passou a ser denominado de Instituto do Patrimônio Histórico e Artístico Nacional - IPHAN, autarquia federal vinculada ao Ministério da Cultura.

\section{Espécies}

A doutrina costuma classificar as espécies de tombamento, em regra, segundo dois critérios: a eficácia do ato e a manifestação da vontade.

No que se refere ao primeiro critério, eficácia do ato, podemos distinguir o tombamento provisório do definitivo. O primeiro ocorrerá quando ainda está em curso o processo administrativo instaurado para o tombamento; o segundo, somente após a finalização do trâmite administrativo, com a inscrição do bem no respectivo Livro do Tombo.

É preciso ressaltar, contudo, que o STJ entende que o denominado tombamento provisório, na verdade, não constitui um procedimento de tombamento, mas sim uma medida assecuratória de preservação da coisa até a inscrição definitiva em algum dos Livros do Tombo. Através desse ato provisório, o Poder Público declara o valor cultural do bem, 
fazendo surgir, somente a partir daí, a responsabilidade do proprietário de preservar e proteger a coisaxii.

Por outro lado, com base na manifestação da vontade, o tombamento pode ser de ofício, voluntário ou compulsório. A primeira modalidade ocorre quando o instituto incide sobre bens públicos, conforme 0 art. $5^{\circ}$ do Decreto-Lei 25/37, através de simples notificação ao respectivo ente federativo que pertence o bem ou sob cuja guarda estiver a coisa tombada. Com a notificação, o tombamento começa a produzir seus efeitos.

O tombamento voluntário, previsto no art. $7^{\circ}$ do Decreto-Lei 25/37, pode ser verificado em duas hipóteses: a) quando o proprietário solicitar o tombamento e a coisa se revestir dos requisitos necessários para ser considerada como parte integrante do patrimônio cultural nacional; b) quando o proprietário da coisa anuir, por escrito, à notificação que se lhe fizer para a inscrição da coisa no respectivo Livro do Tombo.

$\mathrm{Na}$ modalidade compulsória, disciplinada nos arts. $8^{\circ}$ e $9^{\circ}$ do Decreto-Lei $25 / 37$, o tombamento é realizado sem a anuência do proprietário, através de procedimento administrativo junto ao IPHAN.

Alguns autores, como Di Pietro (2011, p. 142), ainda dividem o tombamento em geral e definitivo. O primeiro se daria quando o instituto atinge apenas um bem determinado; o segundo, quando compreende todos os bens situados em um local (como um bairro ou cidade).

Contudo, a divisão em tombamento geral e definitivo não representa consenso na doutrina. Para Carvalho Filho (Op cit, p. 798), por exemplo, todo tombamento tem caráter individual, ou seja, seus efeitos alcançam somente a esfera jurídica do proprietário da coisa tombada. O chamado tombamento geral corresponde a ato limitativo de natureza genérica e abstrata, o que é incongruente com a natureza do instituto. Assim, se vários imóveis de um bairro são tombados, isso ocorre pelo fato de que foram consideradas, individualmente, como integrantes do patrimônio cultural. Em outras palavras, para abranger cada imóvel considerado como patrimônio cultural, é necessária a individualização do ato de tombamento.

\section{Processo administrativo}

Para que se efetue o registro do bem em um dos Livros do Tombo, é preciso a instauração de um processo administrativo específico, o qual pode variar de acordo com a espécie do tombamento.

Contudo, em qualquer processo administrativo de tombamento, é obrigatória a participação de um órgão técnico. $\mathrm{Na}$ esfera federal, tal órgão é Instituto do Patrimônio Histórico e Artístico Nacional - IPHAN.

Ademais, de todo modo, se constatada, por um órgão técnico, a necessidade de proteger um bem de valor cultural ou natural, é expedida uma notificação ao seu proprietário. A partir desta notificação o bem já se encontra protegido legalmente, não podendo ser destruído e descaracterizado até a decisão final (efeito jurídico denominado de "tombamento provisório").

No caso específico de tombamento de ofício - ou seja, aquele que recai sobre bem público - após a manifestação do órgão técnico, é realizada a inscrição da coisa no respectivo Livro do Tombo, notificando o ente federativo proprietário da coisa ou que a possua em sua guarda. 
Acaso trata-se de tombamento voluntário, por requisição do proprietário, haverá a manifestação do respectivo órgão técnico, para averiguar se o bem se insere no patrimônio cultural nacional. Somente após essa avaliação do órgão técnico, a coisa será registrada no Livro do Tombo.

É possível, ainda, que o proprietário, ainda que não tenha solicitado o tombamento, concorde ou, ainda, não se manifeste contrário à intervenção estatal em sua propriedade, a fim de proteger o patrimônio cultural. Não havendo impugnação no prazo legal (15 dias), a partir da notificação, ou havendo concordância do particular (espécie de tombamento voluntário), a Administração está autorizada a registrar a coisa no correspondente do Livro do Tombo.

Entretanto, os casos mais comuns de tombamento ocorrem mediante iniciativa do Poder Público, seguida de uma resistência por parte do particular proprietário do bem a ser tombado.

Com efeito, após a notificação do órgão técnico, o particular tem o prazo de 15 dias para, se quiser, manifestar-se sobre o tombamento do seu bem. Caso seja apresentada impugnação, o departamento técnico responsável pela iniciativa do tombamento terá 15 dias para apresentar suas razões e, a seguir, o processo será remetido ao Conselho Consultivo do órgão técnico incumbido do tombamento, que poderá anular o processo administrativo, se houve ilegalidade; rejeitar a proposta do órgão técnico, ou; homologá-la, caso seja necessário o tombamento. Tratando-se de procedimento tramitado junto ao IPHAN, a decisão final será proferida pelo Ministro da Cultura (Lei $n^{\circ} 6.292$ de 15 de dezembro de 1975).

O Presidente da República, atendendo a motivos de interesse público, poderá determinar, de ofício ou em grau de recurso interposto por qualquer legítimo interessado, que seja cancelado o tombamento de bens pertencentes a quaisquer dos entes federativos ou a entidade a eles vinculadas (Decreto-Lei $\mathrm{n}^{\circ} 3.866$ de 29 de novembro de 1941). Para Carvalho Filho (cf. Op cit, p. 802), esse recurso é considerado como hierárquico impróprio. Por sua vez, Lopes Meirelles (Op cit, p. 468) critica essa competência do Presidente da República, afirmando que

não é de se louvar o poder discricionário que se concedeu ao Presidente da República em matéria histórica e artística, sobrepondo-se seu juízo individual ao do colegiado [...]. A autoridade desse órgão, especializado na matéria, não deveria ficar sumariamente anulada pelo julgamento subjetivo ou político do Chefe da Nação. A instituição desse recurso deve-se, naturalmente, à origem ditatorial do diploma que o estabeleceu, em cujo regime o Presidente da República absorvia todos os poderes e funções, ainda que estranhos à sua missão governamental.

É importante observar que, em todo caso, o processo administrativo deve observar os princípios constitucionais do devido processo legal da ampla defesa e do contraditório (art. $5^{\circ}$, LIV e LV, da CF).

Cumpre lembrar que, embora sejam raros os casos, nada obsta que a Administração, revendo seu próprio ato, em legítimo exercício do seu poder-dever de autotutela, possa anular um procedimento administrativo de tombamento, por vício de legalidade, ou, ainda, revogá-lo, com fundamento no interesse público. Tais espécies de cancelamento de tombamento têm sido denominadas de destombamento . 
Por fim, é preciso frisar que o tombamento é constituído por ato exclusivo do Poder Executivo. Nesse sentido, o Supremo Tribunal Federal julgou inconstitucional ato do Poder Legislativo que pretende alterar as condições de tombamento regularmente instituído pelo Poder Executivo, por agredir o princípio da harmonia entre os Poderes ${ }^{\mathrm{xiv}}$.

\section{Efeitos do tombamento}

Com a finalização do processo administrativo, diversos são os efeitos jurídicos decorrentes do tombamento previstos Decreto-Lei $n^{\circ} 25 / 37$. Tais conseqüências referem-se, principalmente, às restrições ao uso e à alienação do bem tombado.

Para Di Pietro, os efeitos em face do proprietário podem ser divididos em três tipos de obrigações: positivas (de fazer); negativas (de não fazer), e; de suportar.

As obrigações positivas impõem aos titulares dos bens o dever de promover medidas de conservação necessárias sua preservação. Na ausência de condições financeiras para a adoção dessas medidas, o proprietário do bem deve informar ao Poder Público; em caso de desrespeito a tal disposição, poderá ser aplicada multa correspondente ao dobro do valor em que foi avaliado o dano sofrido pela coisa (art. 19).

Sob pena de nulidade da do negócio jurídico, em se tratando de alienação onerosa, haverá direito de preferência da União, dos Estados e Distrito Federal e dos Municípios, nessa ordem. Além da nulidade, também são previstos, se violado o direito de preferência, o sequestro do bem e a imposição, em face do alienante e do adquirente, de multa de $20 \%$ do valor da coisa - essas sanções são aplicadas pelo Poder Judiciário. O direi- to de preferência não inibe o proprietário de gravar livremente a coisa tombada, de penhor, anticrese ou hipoteca (art. 22 e seus parágrafos). Em se tratando de bem público, haverá a possibilidade excepcional de alienação, desde que se trate de transferência para outro ente federativo (art. 11).

No que se refere às obrigações negativas, o proprietário fica proibido de destruir, demolir, ou modificar as coisas tombadas. Para repará-las, pintá-las ou restaurá-las, é necessária a prévia autorização do órgão técnico responsável, sob pena de multa de $50 \%$ do dano causado (art. 17). Em caso de bem móvel, o titular não pode retirá-lo do país, sem o prévio consentimento do órgão técnico, a não ser que seja por um prazo curto, para fins de intercâmbio cultural; caso seja desrespeitada essa regra, a coisa fica sujeita a sequestro e o seu proprietário às penas previstas para o crime de contrabando e multa (art. 15).

De acordo com o Decreto-Lei regulador do tombamento, é prevista, ainda, a obrigação de suportar: o titular deve permitir e contribuir para a fiscalização do bem pelo órgão técnico estatal, sob pena de sofrer sanção pecuniária.

Não são apenas os proprietários que sofrem restrições. $O$ Decreto-Lei $n^{\circ}$ 25/37 determina que, em se tratando de imóveis, os vizinhos não podem, sem prévia autorização do órgão técnico competente, fazer construção que impeça ou reduza a visibilidade da coisa tombada, nem sobre ela colocar anúncios ou cartazes, sob pena de ser determinada a destruição da obra ou a retirada do objeto, impondose, neste caso, multa de $50 \%$ do valor do objeto retirado.

Segundo Di Pietro (Op cit., p. 146), o instituto utilizado, no caso da vizin- 
hança de imóveis tombados, tem natureza de servidão administrativa, em que dominante é a coisa tombada, e serviente, os prédios vizinhos. Em suas palavras, trata-se de servidão que "resulta automaticamente do ato do tombamento e impõe aos proprietários dos prédios servientes obrigação negativa de não fazer construção que impeça ou reduza a visibilidade da coisa tombada e de não colocar cartazes ou anúncios".

Ressalte-se que apenas mediante a presença de dois requisitos é possível se estabelecer a referida servidão administrativa: a vizinhança da coisa tombada e a construção que impeça ou reduza sua visibilidade.

Por outro lado, um ponto que gera dissenso doutrinário é saber se o tombamento gera direito à indenização em favor do proprietário. Sobre o tema, há autores que defendem sempre existir direito à indenização (MELLO, 2004, p. 364).

Entretanto, para grande parte dos autores, o direito à indenização não é automático em caso de tombamento. Como explica Carvalho Filho (Op. cit., p. 803),

nem há amparo constitucional ou legal para tal conclusão, nem há, como regra, prejuízo decorrente do ato, que retrata mera restrição ao uso da propriedade. Além disso, é preciso considerar que, dependendo da singularidade da situação, pode $o$ ato de tombamento gerar vantagens decorrentes da valorização do bem, especialmente bem imóvel, e não prejuízo, para o proprietário. É o caso, por exemplo, de tombamento de edificações em avenida central da cidade, utilizadas por lojas comerciais de diversos ramos; o tombamento, nesse caso, alia-se ao aspecto turístico, ensejando a atração de maior número de consumidores.
Entretanto, é preciso destacar que será devida a indenização, de qualquer modo, desde que comprovado o prejuízo capaz de gerar o dever de indenizar. Assim, provados os requisitos caracterizadores da responsabilidade civil extracontratual do Estado, faz jus o proprietário à indenização decorrente do tombamento.

Através da ação civil pública, prevista na Lei $n^{\circ} 7.347$, de 24 de julho de 1985, é possível o ajuizamento de demanda judicial para fins de garantir a proteção ou o ressarcimento por danos referentes aos bens de valor histórico (art. $\left.1^{\circ}, \mathrm{III}\right)$.

Outrossim, ainda que não previsto expressamente na Lei 4.717/1965, a jurisprudência vem entendendo que tal diploma deve ser interpretado para possibilitar, por meio da ação popular (art. $5^{\circ}$, inc. LXXIII, da CF), a mais ampla proteção aos bens e direitos associados ao patrimônio público, em suas várias dimensões, incluindo o patrimônio cultural ${ }^{x v}$.

\section{Considerações finais}

De acordo com o exposto, percebese que, a partir do século passado, há um compromisso cada vez mais sedimentado dos Estados em proteger os valores culturais da humanidade.

Na seara internacional, esse fenômeno surgiu, principalmente, com o contexto presenciado após a Segunda Guerra Mundial, com o apoio de organismos internacionais como a ONU, que auxiliam o desenvolvimento do processo de cooperação para a proteção do patrimônio cultural de nosso planeta.

No Brasil, foi com a Constituição de 1988 que a defesa da cultura nacional foi levada ao maior nível normativo interno. 
O Estado, mais do que nunca, reconhece seu dever de garantir e promover os movimentos culturais de nosso povo.

Para tanto, o Estado brasileiro dispõe de diversos mecanismos administrativos, um deles, o tombamento, destinado à proteção de bens que representam um relevante valor cultural de nosso país.

Assim, é possível visualizar que o instituto do tombamento, regulado pelo Decreto-Lei $n^{\circ} 25 / 37$, vem tomando um papel cada vez mais importante na preservação de bens que integram nosso patrimônio nacional.

Esse instituto gera obrigações de ordem positiva (de fazer), negativa (não fazer) e de suportar (permitir e cooperar para a fiscalização do Estado). Para sua efetivação, é preciso a instauração de processo administrativo que garanta os princípios constitucionais do devido processo legal, da ampla defesa, do contraditório. Ao final, o tombamento é concretizado através do registro do bem em Livros do Tombo.

Finalmente, é preciso ressaltar que o processo de utilização do tombamento ainda está em fase de desenvolvimento em nosso país. É necessário um trabalho de conscientização, da sociedade e do Estado (MANZATO, s.d.), para que os parâmetros de identificação dos bens a serem tombados, principalmente os previstos no Decreto-Lei $n^{\circ}$ 25/37, venham a se adequar ao sentido da Carta Política de 1988.

\section{Bibliografia:}

BENJAMIN, Antonio Herman de Vasconcellos e. Direito constitucional ambiental brasileiro. In: CANO-
TILHO, José Joaquim Gomes; LEITE, José Rubens Morato (Org.). Direito constitucional ambiental brasileiro. São Paulo: Saraiva, 2007. parte II, p. 57-130. CARVALHO FILHO, José dos Santos. Manual de direito administrativo. São Paulo: 2012.

COELHO, Edihermes Marques; FERREIRA, Ruan Espíndola. Estado de Direito Ambiental e Estado de Risco. Cadernos de Direito, Piracicaba, v. 11(20): 67-80, jan.-jun. 2011.

CRETELLA JÚNIOR, José. Dicionário de direito administrativo. Rio de Janeiro: Forense, 1978.

DI PIETRO, Maria Sylvia Zanella. Direito Administrativo. São Paulo: Atlas, 2011.

MANZATO, Maria Cristina Biazão. Proteção ao patrimônio cultural brasileiro: o tombamento e os critérios de reconhecimento dos valores culturais. Disponível em: <www.aprodab.org.br/ eventos/.../teses/mariacbmanzato01.doc>. Acesso em 22.nov.2014

MEIRELLES, Hely Lopes. Direito administrativo brasileiro. São Paulo: Malheiros, 1998.

MELLO, Celso Antônio Bandeira de. Curso de direito administrativo. São Paulo: Malheiros, 2004.

MOREIRA NETO, Diogo de Figueiredo. Curso de direito administrativo. Rio de Janeiro: Forense, 1989.

PIOVESAN, Flávia. Direitos humanos e o direito constitucional internacional. São Paulo: Max Limonad, 2004.

RAMOS, André de Carvalho. Teoria geral dos direitos humanos na ordem internacional. Rio de Janeiro: Renovar, 2005.

REALE, Miguel. Filosofia do Direito. São Paulo: Saraiva, 2002.

RECASENS SICHES, Luis. Tratado General de Filosofia del Derecho. México: Porrua, 1975.

SILVA, Fernando Fernandes da. Turismo Internacional e Proteção do Patrimônio Cultural e Natural da Humanidade. In: PHILIPPI JR, Arlindo; RUSCHMANN, Doris V. M. Gestão ambiental e sustentabilidade no turismo. Barueri, SP: Manole, 2010, p. 83-95.

SILVA, José Afonso da. Direito ambiental constitucional. São Paulo: Malheiros, 1994. 


\section{Recebido em 20/01/2015 Aprovado em 15/06/2015}

i Renato José Ramalho Alves, articulador em Negociações Internacionais pelo Engajamundo. Pesquisador na Universidade Federal da Paraíba, Brasil. Contato: renatojra@gmail.com

ii Fábio Brito Ferreira, sócio administrador do F. Brito Advogados Associados, formado pelo Centro Universitário de João Pessoa, Brasil. Contato: fabio@fbrito.adv.br

iii Cf. ONU - Organização das Nações Unidas. Carta das Nações Unidas de 1945. Disponível em <http://www.direitoshumanos.usp.br/ index.php/ONU-Organiza\%C3\%A7\%C3\%A3odas-Na\% C 3\% A 7 \% C 3\%B 5 es-Unidas/cartageral-das-nacoes-unidas.html>. Acesso em: 20.nov. 2014 .

iv Op. cit., p. 92.

v ONU - Organização das Nações Unidas. Pacto Internacional dos Direitos Econômicos, Sociais e Culturais de 1966. Disponível em <http://bioeticaediplomacia.org/ wp-content/uploads/2013/12/1966-Pacto-Internacionalsobre-os-Direitos-Econ\%C3\%B3micos-Sociais-e-Culturais.pdf>. Acesso em: 21.nov.2014.

vi ONU - Organização das Nações Unidas. Pacto Internacional dos Direitos Econômicos, Sociais e Culturais de 1966. Disponível em < http://unesdoc.unesco. org/images/0013/001333/133369por.pdf>. Acesso em: 21.nov.2014.

vii É possível, grosso modo, relacionar essa Lista com o instituto brasileiro do tombamento, objeto do presente trabalho, eis que ambos visam o reconhecimento e a proteção de bens ou locais de grande importância histórica e cultural.

viii OEA - Organização dos Estados Americanos.

ix Através do Decreto 91.144 de 15 de março de 1985. Antes desse momento, o governo federal atuava em matérias culturais por meio do Ministério de Educação e Cultura.

$x$ Esses locais não só foram tombados pelo Estado brasileiro, como também foram declarados Patrimônios Mundiais pela UNESCO, respectivamente, em 1980, 1982, 1985. xi "Poder Público é expressão genérica que se refere a todas as entidades territoriais públicas" in: SILVA, José Afonso da. Direito ambiental constitucional. São Paulo: Malheiros, 1994, p. 49.

xii Cf. STJ - REsp 753.534/MT, Rel. Ministro Castro Meira, Segunda Turma, julgado em 25/10/2011, DJe $10 / 11 / 2011$

xiii Sobre o tema, v. CRETELLA JÚNIOR, José. Dicionário de direito administrativo. Rio de Janeiro: Forense, 1978, p. 519.

xiv STF - ADI 1706/DF, rel. Min. Eros Grau, Julgado em 09 de abril de 2008 (Informativo 501).

xv STJ - AgRg no REsp: 1151540 SP 2009/0191197-4, Data de Julgamento: 20/06/2013, T1 - PRIMEIRA TURMA, Relator Ministro Benedito Gonçalves, Data de Publicação: DJe 26/06/2013. 